\title{
Peningkatan Pembelajaran IPA Fisika Tutor dan Mahasiswa S1 PGSD-UT dalam Multikultural di Provinsi Nanggroe Aceh Darussallam melalui Penggunaan Power Point dan Internet Interaktif
}

\begin{abstract}
Mujadi
UPBJJ-UT Banda Aceh

Surat-e: trimurtiadi@gmail.com

Keragaman budaya dalam proses pembelajaran berbasis IPTEK dengan pola maupun model yang beragam mempunyai makna yang sama untuk mencapai tujuan dari pembelajaran itu sendiri. Semua pembelajaran akan lebih bermakna dan punya arti jika didalamnya terkandung suatu kebebasan, keadilan, kesederjatan, dan perlindungan terhadap hak-hak manusia. Secara jelas hakekat pendidikan multikultural mempersiapkan seluruh mahasiswa bekerja secara aktif menuju kesamaan struktur. Di era globalisasi ini sistem pendidikan harus mampu menerima dan menyerap serta mengembangkan perkembangan Ilmu Pengetahuan Teknologi dan Seni sebagai bagian penting untuk meningkatkan kualitas pembelajaran. Pemanfaatan komputer sebagai media pembelajaran yang saat ini telah tersebar di seluruh pelosok tanah air jauh panggang dari api. Keragaman budaya (mulikultural)tidak menghalangi penggunaan Power Point dan Internet Interaktif (PPI) untuk pendidikan yang bertujuan meningkatkan kemampuan mahasiswa/siswa untuk penguasaan konsep IPA Fisika, kemampuan berinovasi, serta meningkatkan keterampilan pada proses pembelajaran. Hasil monitoring tutorial IPA dengan menggunakan PPI berdampak positif secara dua arah, yaitu tutor dan mahasiswa. Teori yang disimulasikan dengan model Power Point dan Internet Interaktif merupakan pembelajaran yang sangat interaktif dan meningkatkan motivasi pembelajaran serta bertambahnya tingkat kemandirian belajar sehingga mendapatkan achievement belajar secara optimal.
\end{abstract}

Kata kunci: IPTEK, konsep, inovasi, dan terampil

\section{Pendahuluan}

Provinsi Aceh atau dikenal dengan Nanggroe Aceh Darussallam merupakan wilayah Indonesia yang berada diujung barat dan dimulai dari kilo meter $0^{\circ}$ (nol) pada peta Indonesia. Povinsi dengan $23 \mathrm{Kab} /$ Kota dan geografis alam yang sangat asri total penduduknya mencapai \pm 4 juta jiwa. Keberagaman suku bangsa dan budaya sesuai dengan nama yang tertera, yaitu" A C E H" yang berarti Arab, Cina, Eropa (portugis), dan Hindia. Dalam hal pemerataan pendidikan di Aceh sedang giat-giatnya digalakkan dengan memberikan bantuan bea siswa bagi calon guru dan guru, serta mendirikan sekolah-skolah didaerah-daerah 3T.

Kita telah menyadari bahwasannya Negara Indonesia terbentuk oleh kurang lebih 13000 pulau besar dan kecil, dan tentu mempunyai keragaman suku, ras, bahasa, status social, religi, dan letak geografis. Melihat jumlah penduduk saat ini telah mencapai 200 juta jiwa, terdiri dari 300 suku yang menggunakan hampir 200 bahasa yang berbeda, maka tidak dipungkiri lagi Indonesia merupakan salah satu Negara yang multicultural terbesar di dunia. Kebenaran hal tersebut dapat dilihat dari sosio kultur maupun geografis yang begitu beragam dan luas. Selain itu juga masyarakat Indonesia menganut agama dan kepercayaan yang beragam seperti; Islam, Katolik, Kristen Protestan, Hindu, Budha, Konghucu, serta berbagai macam aliran kepercayaan. Salah satu isi yang tidak dapat ditawar lagi adalah masalah keseragaman dan keadilan Pendidikan yang berfungsi mencerdaskan kehidupan bangsa dan mampu meneruskan secara estafet membangun Indonesia menjadi Negara yang maju berdaulat adil dan makmur. Melihat situasi dan kondisi masyarakat yang beragam kulturnya pemilihan 
Pendidikan yang paling memungkinkan adalah Pendidikan Multikultural.

Pendidikan multikultural didefinisikan sebagai sebuah kebijakan sosial yang didasarkan pada prinsip-prinsip pemeliharaan budaya dan saling memiliki rasa hormat antara seluruh kelompok budaya di dalam masyarakat. Pembelajaran multikultural pada dasarnya merupakan program pendidikan bangsa agar komunitas multikultural dapat berpartisipasi dalam mewujudkan kehidupan demokrasi yang ideal bagi bangsanya (Banks, 1993). (http://lubisgrafura.wordpress.com/2007/09/10/).

Dalam konteks yang luas, pendidikan multicultural(berbasis multikultural) mencoba membantu menyatukan bangsa secara demokratis, dengan menekankan pada perspektif pluralitas masyarakat di berbagai bangsa, etnik, kelompok budaya yang berbeda. Dengan demikian sekolah dikondisikan untuk mencerminkan praktik dari nilai-nilai demokrasi. Kurikulum menampakkan aneka kelompok budaya yang berbeda dalam masyarakat, bahasa, dan dialek; dimana para pelajar lebih baik berbicara tentang rasa hormat di antara mereka dan menunjung tinggi nilainilai kerjasama, dari pada membicarakan persaingan dan prasangka di antara sejumlah pelajar yang berbeda dalam hal ras, etnik, budaya dan kelompok status sosialnya.

\section{Perkembangan ilmu pengetahuan dan teknologi abad ke-21}

Kemampuan guru untuk menjawab tantangan mengajar Abad 2Itersebut juga sebagai salah satu aspek yang harus diperhitungan untuk menjadi guru idola pada siswa pada era globalisasi. Ilustrasi penerapan masingmasing tantangan ke dalam tugas guru, sebagai berikut:

I. Mengajar dan Teknologi: memanfaatkan berbagai produk teknologi untuk belajar siswa. Guru yang dapat mengantar siswa mengarungi dunia ilmu pengetahuan dan teknologi, (H. Tilaar, 1998)

2. Mengajar dengan pandangan baru tentang kemampuan: dapat melalui menenpatakan siswa memiliki kecerdasan ganda dalam prosespembelajaran, (Multiple Intellegences, Gardner, Howard, I993)

3. Mengajar dengan pilihan: pembelajaran dapat menerapkan multi bahasa, belajar di laboratorium, praktik lapangan di negara lain(belajar sistem belapis), belajar praktik dalam fenomena nyata, pembelajaran proyek. Guru mampu mandiri dalam pembelajaran, konservatif dan inovatif (Scheerens, 1992, dalam Sukamto,dkk. I999)

4. Belajar dan akuntabilitas: dalam pembelajaran guru member kepuasan layanan,mendokumentasikan proses dan hasil kinerja, terbuka untuk dinilai oleh pelanggan dan atasan, melakukan refleksi diri atas kinerjanya

5. Mengajar untuk pembelajran aktif: memanfaatkan seluruh indera siswa untuk belajar: apa yang dilihat, dengar, kecap, bahui, sentuh, lakukan, bayangkan, intuisikan, rasakan (Dryden \& Vos, I999)

6. Mengajar untuk kontruksi makna: hasil belajar berupa keterampilan akademik dan kematangan sikap (sofe skill), atau pemilikan kecakapan hidup, atau siswa dapat menerapkan pengetahuan dalam memecahkan masalah hidup.

7. Mengajar dalam masyarakat multikultural: berlaku adil kepada setiap siswa tanpa memandang "RAS", mempunyai keteladanan moral dan rasa estetika yang tinggi dan melatih siswa untuk Sanggup bersaing dan bersanding, bekerjasama dengan siapapun (menerapkan pendidikan perdamaian, dan pendidikan internasional)

Tantangan guru tersebut diwadahi, dalam pemilikan kompetensi pendidik. Dalam pembelajaran diharapkan guru dapat menekankan pada kemampuan siswa sebagai dasar penetapan bahan ajar yang sesuai. Kemampuan guru ini tercakup dalam kompetensi pedagogik dan kompetensi profesional.

\section{Pemanfaatan teknologi dalam pembelajaran}

Penggunaan media pembelajaran yang berbasis Teknologi Informasi dan Komunikasi (TIK) merupakan hal yang tidak mudah. Dalam menggunakan media tersebut harus memperhatikan beberapa teknik agar media yang dipergunakan itu dapat dimanfaatkan dengan maksimal dan tidak menyimpang dari tujuannya,. Arief S. Sadiman ( 1996 : 83 ) mengatakan bahwa :

\section{a. Media Pembelajaran dengan Menggunakan Komputer}

Aplikasi komputer dalam bidang pembelajaran memungkinkan berlangsungnya proses belajar secara individual (individual learning). User komputer dapat melakukan interaksi secara langsung dengan sumber informasi. Perkembangan (computer network/Internert) teknologi komputer jaringan, saat ini telah memungkinkan usernya melakukan interaksi dalam memperoleh pengetahuan dan informasi yang diinginkan secara langsung. Berbagai bentuk interaksi pembelajaran dapat berlangsung dengan tersedianya medium komputer. Beberapa lembaga pendidikan jarak jauh di sejumlah negara yang telah maju, memanfaatkan media ini sebagai sarana interaksi. Pemanfaatan ini didasarkan pada kemampuan yang dimiliki oleh komputer dalam memberikan umpan balik (feedback) 
yang segera kepada para usernya. Contoh penggunaan internet ini adalah :

a. Universitas terbuka dalam penyelenggaraan kegiatan Universitas Terbuka Jarak Jauh, disamping mahasiswa mendapat modul untuk proses belajar mengajar, dia juga dapat mengakses informasi melalui internet.

b. Kuliah lewat Internet oleh IBUteledukasi.com. Universitas virtual IBUteledukasi ini didirikan oleh Adi sasono, Ketua Ikatan Cendekiawan Muslim Indonesia (ICMI) bekerjasama dengan Universitas Tun Abdul Razak (Unitar) Malaysia yang sudah lebih dulu menyelenggarakan perkuliahan online.

c. Pada pendidikan jarak jauh Fakultas Kedokteran Universitas Gajah Mada.

d. Interaksi pembelajaran pada program Magister Manajemen Rumah Sakit dan Magister Manajemen Pelayanan Kesehatan dilakukan melalui surat elektronik (e-mail), mahasiswa harus menjawab $75 \%$ pertanyaan melalui e-mail.

e. Sejak tahun I994 UI telah mengembangkan infrastruktur informasi yang dikenal dengan nama Jaringan Universitas Indonesia Terpadu (JUITA). JUITA menghubungkan sebelas fakultas dan lembagalembaga penting yang ada di UI dengan menggunakan jaringan serat optik ( Sri Hartati, dkk 1997 dalam Benny A. Pribadi dan Rosita, Tita, 2000).

Selain komputer digunakan sebagaiakses internet, komputer juga dapat dimanfaatkan sebagai median pemebelajaran dengan menggunakan power point (PP). Power point sebagai media pembelajaran sangat mudah didesain ataupun dirancang oleh siapapun sepanjang memiliki kemampuan dan keterampilan mengoperasikan komputer dengan baik. Dengan demikian hasil yang dibuatnya dapat diperbanyak dalam bentuk CD dan mudah dibawa kemana-mana serta murah harganya. Dibandingkan dengan penggunaan internet memang sangat berbeda, karena penggunaan internet harus dilengkapi oleh perangkat Modem yang cukup mahal. Namun demikian penggunaan Modem sangat membantu bila digunakan sebagai bagian dari proses pembelajaran praktikum IPA di SD.

\section{b. Penggunaan Jaringan Komputer/Internet untuk}

\section{Kegiatan Pembelajaran}

Teknologi jaringan komputer/internet memberi banyak manfaat bagi pemakainya untuk melakukan komunikasi secara langsung maupun tidak. Hal ini dimungkinkan dengan diciptakannya sebuah alat bernama modem. Jaringan komputer/internet memberi kemungkinan bagi pesertanya untuk melakukan komunikasi tertulis maupun tidak dan saling bertukar pikiran tentang kegiatan belajar yang mereka lakukan. Jaringan komputer dapat dirancang sedemikian rupa agar dosen /guru dapat berkomunikasi dengan mahasiswa/siswa dan mahasiswa/siswa dapat melakukan interaksi belajar dengan mahasiswa/siswa yang lain. Interaksi pembelajaran dengan menggunakan jaringan komputer tidak saja dapat dilakukan secara individual, tetapi juga berkelompok. Pemanfaatan jaringan komputer dalam sistem pendidikan jarak jauh dikenal juga dengan istilah Computer Conferencing System (CCF). Biasanya sistem ini dilakukan melalui surat elektronik (email). Beberapa kelebihan pemanfaatan jaringan komputer dalam sistem pendidikan jarak jauh yaitu; memperkaya modelmodel tutorial, dapat memecahkan masalah belajar yang dihadapi mahasiswa/siswa dalam waktu yang lebih singkat, dan dapat mengatasi hambatan ruang dan waktu dalam memperoleh informasi. Computer Conferencing System memberi kemungkinan bagi mahasiswa dan dosen/guru agar melakukan interaksi pembelajaran langsung antar individu, individu dengan kelompok, dan kelompok dengan kelompok (Mason, 1994 dalam Benny A. Pribadi dan Tita Rosita, 2002:13-I4).

\section{Pembelajaran berbasis multikultural pada matakuliah berpraktik di UT}

Universitas Terbuka (UT) menerapkan sistem belajar "terbuka" dan "jarak jauh”. Makna "terbuka” adalah tidak ada pembatasan usia, tahun ijazah, masa belajar, waktu registrasi, berapa kali mahasiswa mengikuti ujian dan sebagainya. Mahasiswa dituntut mampu untuk merancang penyelesaian pendidikannya sendiri dan tidak ada sistem drop out. Batasan yang ada hanyalah setiap mahasiswa UT telah menamatkan jenjang pendidikan menengah (SMA atau yang sederajat).Istilah "jarak jauh” berarti pembelajaran tidak dilakukan secara tatap muka karena keterpisahan antara mahasiswa dan dosen, melainkan menggunakan media, baik media cetak (modul) maupun noncetak (audio/video, komputer/internet, siaran radio dan televisi).

Penyelenggaraan pendidikan di UT dirancang untuk seluruh daerah mempunyai standar yang sama, sehingga kualitas hasil kelulusannya diharapkan akan mempunyai hasil yang sama pula. Mengingat jangkauan dan cakupan mahasiswa UT ada di seluruh pelosok tanah air, dapat dipastikan bahwa penyelenggaraan pendidikan di UT juga menerapkan pembelajaran berbasis multikultural. Kaitannya dengan peningkatkan kompetensi guru IPA yang cerdas dan berpengetahuan agaknya model pembelajararan jarak jauh dapat dijadikan sebagai sebuah solusi meningkatkan kualifikasi pendidikan guru ketika daya tampung sistem 
pendidikan tatap muka sangat terbatas. Namun demikian matakuliah berpraktik ini perlu mendapatkan perhatian yang serius dalam penyelenggaraannya khususnya pelaksanaan di lapangan. Pembekalan kegiatan matakuliah berpraktik saat ini di UT telah dilengkapi dengan Kit IPA beserta pedomannya dalam CD maupun Modul. Pada kenyataannya kegiatan pembelajaran pada mata kuliah berpraktek PDGK 4107 dengan bobot tiga (3) SKS banyak mengalami kendala, sehingga terjadi kekawatiran tidak tercapainya sasaran maupun tujuan dari pembelajaran itu sendiri. Hasil monitoring dan evaluasi kegiatan Praktikum IPA di beberapa pokjar yang ada di UPBJJ-UT Banda Aceh, antara lain:

a. Pokjar Pidie Jaya

b. Pokjar Takengon

c. Pokjar Tapaktuan

d. Pokjar Bireuen dan Lokhseumawe.

menunjukkan kondisi yang sangat memprihatinkan ditinjau dari kelengkapan alat dan bahan yang digunakan, yaitu Kit IPA yang dimiliki 90\% kondisinya dalam keadaan tidak layak pakai. Kondisi ini belum pernah mendapatkan perbaikan dan perubahan dan telah berjalan cukup lama, keragaman budaya dari kelompok mahasiswa sebagai guru dalam menanggapi perlunya pembelajaran IPA yang baik di SD sangat bervariasi secara merata antara yang suka dan tidak suka. Dari data yang diperoleh terdapat keragaman bawaan dari budaya dimana mahasiswa yang juga sebagai guru SD, terdiri dari beberapa suku asli dan pendatang antara lain :

a. Pokjar Pidie Jaya dengan keragaman budaya antara lain:

Aceh keturunan India*, Jawa trans, Padang, Banten,

Batak, dll.

b. Pokjar Takengon dengan keragaman budaya, antara

lain: Gayo*, Jawa trans, Sunda, Padang, Batak, dll.

c. Pokjar Tapaktuan dengan keragaman budaya, antara lain: Jawa trans ${ }^{\text {¿* }}$, Padang, Batak, dll

d. Pokjar Bireuen dan Lokseumawe dengan keragaman budaya, antara lain: Aceh *, India, Cina, Gayo

Melihat kondisi proses pembelajaran IPA berpraktek melalui penggunaan Kit IPA kurang diminati oleh mahasiswa, maka perlu dilakukan tambahan model berpraktikum yang dapat diterima oleh semua mahasiswa sebagai guru dengan cara yang mudah dan menyenangkan. Model ini harus dapat memberikan kontribusi pencapaian sasaran dan tujuan dari pembelajaran IPA berpraktik khususnya bidang Fisika. Penambahan model diharapkan mampu memberikan pengetahuan tambahan bagi mahasiswa sebagai guru SD untuk lebih terampil dan inovativ dalam mengembangkan pengetahuannya di bidang IPA khususnya Fisika.

\section{Kombinasi Kit IPA, power point dan internet pada pembelajaran IPA fisika}

Penggunaan alat peraga Kit IPA yang dikombinasikan dengan power point (PP), serta simulasi melalui internet pada kegiatan praktikum IPA Fisika merupakan suatu alternatif yang perlu diperhitungkan manfaatnya. Mengingat perangkat komputer dan jaringan internet telah mencapai seluruh pelosok tanah air di Indonesia. Ruang PKG yang ada di setiap kecamatan telah dilengkapi dengan komputer yang cukup dan memadai. Di era globalisasi teknologi informasi dan komunikasi (TIK) telah mampu diadopsi menjadi bagian dari basis pembelajaran yang dikenal pembelajaran berbasis TIK. Pembelajaran berbasis TIK bukan berasal dan diciptakan yang bersifat kesukuan, namun bersifat general dan dapat diterima oleh semua lapisan budaya masyarakat, golongan, dan dapat dilakukan secara individu maupun kelompok.

Yang menjadi pertanyaan sekarang adalah ”Apakah dengan mengkombinasikan penggunaan Kit IPA, PP, dan Internet pada kegiatan paraktikum IPA Mata Kuliah PDGK 4I07 dapat mempermudah mahasiswa sebagai guru menguasai konsep IPA/fisika, terampil, dan inovatif pada pembelajaran IPA di SD?"

Sedangkan pengkombinasian antara kit IPA, PP, dan internet bertujuan memberikan kemudahan bagi mahasiswa sebagai guru SD menguasai konsep IPA Fisika, kemampuan berinovasi dalam pembelajaran IPA, dan meningkatan keterampilannya dalam merangkai maupun membuat alat peraga IPA.

\section{Pembahasan}

\section{Kemampuan pemahaman konsep IPA fisika tutor dan mahasiswa setelah menggunakan kit IPA}

Perangkat kit IPA pada matakuliah PDGK 4 I07 pada program studi SI Pendidikan Dasar di Universitas Terbuka sebaiknya digunakan setelah mahasiswa telah menguasai konsep IPA/Fisika dengan baik dan benar. Setelah melakukan pengamatan dari tiga Pokjar yang ada di UPBJJUT Banda Aceh, uji coba penggunaan kombinasi Kit IPA, PP, dan Internet dilakukan pada Pokjar Sigli dengan pertimbangan keragaman budaya mahasiswa yang dianggap paling memenuhi kriteria multikultural dan jumlah kelas berpraktikum juga banyak. Dengan menggunakan sampel enam (6) tutor praktikum IPA Fisika dan 33 mahasiswa semester empat dan enam SI Pendas yang mengikuti mata kuliah PDGK 4I07 diberikan tes setelah melakukan 
pratikum IPA/Fisika dengan menggunakan Kit IPA pada pokok bahasan Rangkaian Listrik Sederhana masing-masing 8 butir soal. Adapun butir-butir soal yang diberikan terdiri atas tiga bagian, yaitu arus, sumber tegangan, dan rangkaian, diantaranya:

a. Soal nomor I,3, 4 tentang aliran arus pada rangkaian tertutup tersusun seri maupun paralel.

b. Soal nomor 5 dan 6 tentang susunan batere seri maupun paralel

c. Sola nomor 2,7, dan 8 tentang perpaduan susunan batere dan bentuk rangkaian.

Adapun hasil yang didapatkan adalah sebagai berikut.

Tabel I. Kelompok Mahasiswa Rangkaian Listrik Sederhana dengan menggunakan Kit IPA

\begin{tabular}{|c|c|c|c|c|c|c|c|c|c|}
\hline \multirow{2}{*}{ No } & \multicolumn{8}{|c|}{ Nomor Butir Soal Benar(I), salah(0) } & \multirow{2}{*}{$\begin{array}{l}\% \\
\text { benar }\end{array}$} \\
\hline & I & 2 & 3 & 4 & 5 & 6 & 7 & 8 & \\
\hline I & I & 0 & 0 & 0 & 0 & 0 & 0 & 0 & $\mathrm{I} 2,5$ \\
\hline 2 & I & I & 0 & 0 & I & 0 & I & 0 & 50 \\
\hline 3 & I & I & I & 0 & I & 0 & I & 0 & 50 \\
\hline 4 & I & I & 0 & 0 & 0 & 0 & I & I & 50 \\
\hline 5 & I & I & I & 0 & I & 0 & I & 0 & 62,5 \\
\hline 6 & I & 0 & 0 & 0 & 0 & 0 & I & I & 37,5 \\
\hline 7 & I & I & 0 & I & 0 & 0 & I & 0 & 50 \\
\hline 8 & I & I & 0 & 0 & I & 0 & I & I & 62,5 \\
\hline 9 & I & I & I & 0 & I & 0 & I & I & 75 \\
\hline I0 & I & I & 0 & 0 & I & 0 & I & I & 62,5 \\
\hline II & I & 0 & 0 & 0 & 0 & 0 & 0 & 0 & $\mathrm{I} 2,5$ \\
\hline I2 & I & 0 & 0 & 0 & 0 & 0 & 0 & 0 & $\mathrm{I} 2,5$ \\
\hline 13 & I & I & 0 & 0 & I & 0 & I & I & 62,5 \\
\hline I4 & I & 0 & 0 & 0 & 0 & 0 & 0 & 0 & $\mathrm{I} 2,5$ \\
\hline I5 & I & I & 0 & 0 & I & 0 & I & I & 62,5 \\
\hline I6 & 0 & 0 & 0 & I & I & 0 & I & I & 50 \\
\hline I7 & 0 & 0 & 0 & 0 & 0 & 0 & I & I & 25 \\
\hline I8 & 0 & 0 & 0 & 0 & 0 & 0 & I & I & 25 \\
\hline 19 & 0 & 0 & 0 & 0 & 0 & I & I & I & 37,5 \\
\hline 20 & 0 & 0 & 0 & 0 & 0 & 0 & I & I & 25 \\
\hline 2I & I & 0 & 0 & 0 & I & 0 & I & 0 & 37,5 \\
\hline 22 & I & 0 & 0 & I & I & 0 & 0 & I & 50 \\
\hline 23 & I & 0 & 0 & 0 & 0 & 0 & I & I & 37,5 \\
\hline 24 & I & I & 0 & I & 0 & 0 & I & 0 & 50 \\
\hline 25 & I & I & 0 & 0 & I & 0 & I & I & 62,5 \\
\hline 26 & I & I & I & 0 & I & 0 & I & I & 75 \\
\hline 27 & I & I & 0 & 0 & I & 0 & I & I & 62,5 \\
\hline 28 & I & 0 & 0 & 0 & 0 & 0 & 0 & I & 25 \\
\hline 29 & I & 0 & 0 & 0 & 0 & 0 & 0 & 0 & $\mathrm{I} 2,5$ \\
\hline 30 & I & I & 0 & 0 & I & 0 & I & I & 62,5 \\
\hline $3 \mathrm{I}$ & I & I & 0 & 0 & 0 & 0 & 0 & I & 37,5 \\
\hline 32 & $\mathrm{I}$ & I & 0 & 0 & 0 & 0 & I & $\mathrm{I}$ & 50 \\
\hline
\end{tabular}

\begin{tabular}{llllllllll}
\hline \multirow{2}{*}{ No } & \multicolumn{1}{c}{ Nomor Butir Soal Benar(I), salah(0) } & \multicolumn{1}{c}{$\begin{array}{l}\% \\
\text { benar }\end{array}$} \\
\cline { 2 - 10 } & I & 2 & 3 & 4 & 5 & 6 & 7 & $\mathbf{8}$ & \\
\hline 33 & I & I & 0 & I & 0 & 0 & 0 & 0 & 37,5 \\
\hline Jml & 28 & I8 & 4 & 5 & I8 & I & 24 & 2 I & 45,06 \\
\hline
\end{tabular}

Keterangan Tabel I.

Dari tabel I. yang ada terlihat bahwa secara keseluruhan pemahaman dan kemampuan mahasiswa setelah melakukan praktikum IPA / Fisika khususnya tentang kelistrikan ratarata mencapai 45,06 \% . Hasil ini sangat jauh dari sasaran dan tujuan yang hendak di capai dari pembelajaran itu sendiri. Secara khusus kemampuan dan pemahaman mahasiswa rata-rata sebagai berikut:

I. Soal nomor I,3, 4 tentang aliran arus pada rangkaian tertutup tersusun seri maupun paralel rata-rata mencapai $37 \%$. Pemahaman tentang aliran arus listrik dalam suatu rangkaian, khususnya pada butir soal nomor I terdapat I0 orang mahasiswa/guru mengatakan bahwa arus listrik keluar dari kutub utara menuju kutub selatan.

2. Soal nomor 5 dan 6 tentang susunan batere seri maupun paralel mencapai $19 \%$.

Pada kelompok pertanyaan susunan batere jawaban mahasiswa/guru sangatlah memprihatinkan. Hal ini menunjukkan bahwa konsep yang dipahami sangatlah rendah dan tidak memadahi untuk melaksanakan praktikum tentang listrik. Sebagian besar mahasiswa menjawab jika batere disusun seri tidak dalam sustu rangkaian tegangannya akan semakin terang, timbul terang, volumenya sangat terang, dan ada yang tidak menjawab.

Soal nomor 2,7, dan 8 tentang perpaduan susunan batere dan bentuk rangkaian mencapai $64 \%$. Pada kelompok ini pertanyaan difokuskan pada rangkaian yang dihubungkan dengan susunan batere paralel maupun seri. Dari jawaban mahasiswa ada yang masih menganggap bahwa batere yang disusun seri dalam suatu rangkaian akan bertambah besar dari hasil berbanding lurus, sehingga pada pertanyaan ini hanya I8 mahasiswa yang menjawab benar. Sedangkan untuk pertanyaan lainnya tentang nyala lampu yang dihubungkan dengan susunan batere seri maupun paralel rata-rata menjawab diatas $60 \%$ benar.

Pada kegiatan praktikum ini yang sangat terlihat adalah keterampilan mahasiswa dalam menggunakan bahan kit IPA, baik menggunakan maupun merakitnya amat sangat kurang. Rekaman yang dapat terkumpul dari hasil wawancara terlihat bahwa dari kelompok budaya tertentu 
tidak menyukai atau kurang mampu menggunakan dan merakit kit IPA.

Tabel 2. Kelompok Mahasiswa Rangkaian Listrik Sederhana dengan menggunakan Kombinasi Kit IPA,PP, dan Internet

\begin{tabular}{|c|c|c|c|c|c|c|c|c|c|}
\hline \multirow{2}{*}{ No } & \multicolumn{8}{|c|}{ Nomor Butir Soal Benar(I), salah(0) } & \multirow{2}{*}{$\begin{array}{l}\% \\
\text { benar }\end{array}$} \\
\hline & $\mathrm{I}$ & 2 & 3 & 4 & 5 & 6 & 7 & 8 & \\
\hline $\mathrm{I}$ & $\mathrm{I}$ & $\mathrm{I}$ & 0 & 0 & $\mathrm{I}$ & 0 & $\mathrm{I}$ & $\mathrm{I}$ & 62,5 \\
\hline 2 & I & I & $\mathrm{I}$ & I & I & I & I & $\mathrm{I}$ & 100 \\
\hline 3 & I & $\mathrm{I}$ & $\mathrm{I}$ & I & I & I & $\mathrm{I}$ & $\mathrm{I}$ & 100 \\
\hline 4 & I & $\mathrm{I}$ & I & I & I & I & $\mathrm{I}$ & $\mathrm{I}$ & $\mathrm{IOO}$ \\
\hline 5 & I & $\mathrm{I}$ & $\mathrm{I}$ & I & I & I & $\mathrm{I}$ & $\mathrm{I}$ & 100 \\
\hline 6 & I & I & I & 0 & I & 0 & I & I & 75 \\
\hline 7 & I & I & 0 & 0 & I & 0 & I & I & 62,5 \\
\hline 8 & I & I & I & I & I & I & I & I & $\mathrm{IOO}$ \\
\hline 9 & I & I & I & I & I & I & I & I & $\mathrm{I} 00$ \\
\hline I0 & I & I & I & I & I & 0 & I & I & 87,5 \\
\hline II & I & I & I & 0 & I & 0 & I & I & 75 \\
\hline $\mathrm{I} 2$ & I & I & I & 0 & I & 0 & I & I & 75 \\
\hline $\mathrm{I} 3$ & I & I & I & I & I & I & I & $\mathrm{I}$ & 100 \\
\hline I4 & I & I & 0 & I & 0 & I & I & 0 & 67,5 \\
\hline I5 & I & I & I & I & I & I & I & I & 100 \\
\hline I6 & I & I & I & 0 & I & 0 & I & 0 & 62,5 \\
\hline I7 & I & I & I & 0 & I & I & I & I & 87,5 \\
\hline I8 & I & 0 & I & 0 & I & I & I & I & 75 \\
\hline 19 & I & $\mathrm{I}$ & $\mathrm{I}$ & 0 & I & I & $\mathrm{I}$ & I & 87,5 \\
\hline 20 & I & 0 & 0 & I & I & I & I & I & 75 \\
\hline $2 \mathrm{I}$ & I & I & I & I & I & I & I & I & 100 \\
\hline 22 & I & I & 0 & I & I & 0 & I & $\mathrm{I}$ & 75 \\
\hline 23 & I & I & I & 0 & I & I & I & I & 87,5 \\
\hline 24 & I & I & I & I & I & I & I & I & 100 \\
\hline 25 & I & I & I & I & I & 0 & I & I & 87,5 \\
\hline 26 & I & I & I & I & I & I & I & $\mathrm{I}$ & $\mathrm{I} 00$ \\
\hline 27 & I & I & I & I & I & I & I & I & 100 \\
\hline 28 & I & I & 0 & I & I & 0 & I & I & 75 \\
\hline 29 & I & I & I & I & 0 & I & I & I & 87,5 \\
\hline 30 & I & I & I & 0 & I & I & I & I & 87,5 \\
\hline 3I & I & I & I & I & I & 0 & 0 & I & 75 \\
\hline 32 & I & I & I & I & I & I & I & I & I00 \\
\hline 33 & I & $\mathrm{I}$ & 0 & I & $\mathrm{I}$ & I & 0 & I & 75 \\
\hline Jml & 33 & $3 I$ & 26 & 22 & $3 I$ & 22 & $3 I$ & $3 \mathrm{I}$ & 85,98 \\
\hline
\end{tabular}

Keterangan Tabel 2.

Bila diperhatikan tabel I. dan tabel 2. Hasil antara dari kedua tes tersebut maka terdapat perbedaan yang sangat signifikan. Penguasaan burir-butir soal dari 8 nomor yang ada dapat dipahami dan dikuasai setelah dilakukan tambahan kegiatan simulasi peragaan Power Point (PP) dan peragaan simulasi melalui Internet. Penguasaan konsep yang memfokuskan pada arus, sumber tegangan, dan rangkaian meningkat secara signifikan sebagai berikut; a. Soal nomor I,3, 4 tentang aliran arus pada rangkaian tertutup tersusun seri maupun paralel rata-rata mencapai $81,82 \%$, mengalami peningkatan $44,82 \%$

b. Soal nomor 5 dan 6 tentang susunan batere seri maupun paralel mencapai 80,30\% mengalami peningkatan $61,30 \%$

c. Soal nomor 2,7 , dan 8 tentang perpaduan susunan batere dan bentuk rangkaian mencapai 93,94 mengalami peningkatan 29,92\%.

Selain peningkatan penguasaan konsep arus, tegangan, dan rangkaian para mahasiswa/guru, mempunyai kemampuan lain yang meningkat, yaitu keterampilan dalam merangkai alat dan bahan yang terdapat pada kit IPA, khususnya merangkai rangkaian listrik maupun batere, merancang PP dan mengakses Internet. Sedangkan inovasi yang dihasilkan belum dapat terlihat karena memang membutuhkan waktu dan pengamatan secara kontinyu.

Tabel 3. Kelompok Tutor Rangkaian Listrik Sederhana dengan menggunakan Kit IPA

\begin{tabular}{|c|c|c|c|c|c|c|c|c|c|}
\hline \multirow{3}{*}{$\begin{array}{l}\text { No } \\
\text { Tutor }\end{array}$} & \multicolumn{8}{|c|}{ NOMOR BUTIR SOAL BENAR(I), } & \multirow{3}{*}{$\begin{array}{l}\text { ket } \\
\%\end{array}$} \\
\hline & \multicolumn{8}{|c|}{ SALAH $(0)$} & \\
\hline & I & 2 & 3 & 4 & 5 & 6 & 7 & 8 & \\
\hline I & I & I & $\mathrm{I}$ & $\bar{I}$ & $\mathrm{I}$ & 0 & I & 0 & 75 \\
\hline 2 & I & I & I & 0 & I & 0 & I & 0 & 62,5 \\
\hline 3 & I & I & 0 & I & I & I & I & 0 & 75 \\
\hline 4 & I & I & I & I & I & 0 & I & I & 87,5 \\
\hline 5 & $\mathrm{I}$ & I & $\mathrm{I}$ & 0 & $\mathrm{I}$ & I & $\mathrm{I}$ & 0 & 75 \\
\hline 6 & 0 & I & I & I & 0 & 0 & I & 0 & 50 \\
\hline
\end{tabular}

Tabel 4. Kelompok Tutor Rangkaian Listrik Sederhana dengan menggunakan Kombinasi Kit IPA,PP, dan Internet

\begin{tabular}{|c|c|c|c|c|c|c|c|c|c|c|}
\hline \multirow{3}{*}{$\begin{array}{l}\text { No } \\
\text { Tutor }\end{array}$} & \multicolumn{9}{|c|}{ NOMOR BUTIR SOAL BENAR(I), } & \multirow{3}{*}{$\begin{array}{l}\text { ket } \\
\%\end{array}$} \\
\hline & \multicolumn{9}{|c|}{ SALAH $(0)$} & \\
\hline & $\mathrm{I}$ & 2 & 3 & 4 & 5 & 6 & 7 & & 8 & \\
\hline $\mathrm{I}$ & $\mathrm{I}$ & I & 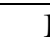 & & $\mathrm{I}$ & $\mathrm{I}$ & $\mathrm{I}$ & $\mathrm{I}$ & $\mathrm{I}$ & 100 \\
\hline 2 & I & I & 1 & & I & I & I & I & I & 100 \\
\hline 3 & I & I & 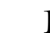 & & I & I & I & I & I & 100 \\
\hline 4 & I & I & 1 & & I & I & I & I & I & 100 \\
\hline 5 & I & I & 1 & & I & I & I & I & $\mathrm{I}$ & I00 \\
\hline 6 & $\mathrm{I}$ & I & 1 & & I & I & C & $\mathrm{I}$ & $\mathrm{I}$ & 87,5 \\
\hline
\end{tabular}

Pada kelompok tutor ini tidak ditindak lanjuti dengan memberikan tes, karena telah dianggap telah menguasai konsep tentang rangkaian listrik dengan baik dan benar. 


\section{Keuntungan menggunakan dan mengkombinasikan Kit IPA, PP, dan Internet}

Penggunaan PP dan internet ternyata banyak memberikan keuntungan dari segi pembelajaran yang berdampak pada meningkatnya pemahaman tutor dan mahasiswa/guru terhadap konsep Fiska. Antara PP dan Internet dapat memberikan subsidi kemampuan untuk berpikir secara logis dan kemampuan untuk mencoba, meniru, dan membuktikan hasil dari suatu pembelajaran berpraktik.

Penggunaan PP dapat memberikan sumbangan pada bagian lain yang tidak terdapat pada simulasi di Internet pada kegiatan praktek yang sama, sehingga jika keduanya dikombinasikan akan memberikan kelengkapan yang lebih sempurna. PP dan Internet akan disajikan sebelum kegiatan praktikum dilaksanakan, sebab PP dan internet akan memberikan panduan cara merakit maupun pemahaman konsep listrik secara lengkap dan mudah untuk dipahami maupun dilaksanakan.

Sebagai contoh pada praktikum tentang listrik, penggunaan PP akan memberikan pemahaman konsep pergerakan arus, nilai tegangan secara teori, dan arus serta tegangan pada suatu rangkaian tertutup. Sedangkan simulasi pada internet tentang rangkaian listrik akan memberikan panduan cara merangkai, menghitung arus maupun tegangan dengan menggunakan alat ukur, dan bagaimana pergerakkan electron pada suatu rangkaian tertutup sederhana.

Dengan demikian sudah seharusnya ada peningkatan secara kuantitas maupun kualitas dengan cara menambah kelengkapan kit IPA dengan CD PP dan pemanfaat internet, sehingga kemampuan mahasiswa/guru SD bertambah yang akhirnya kualitas pembelajaran di SD juga bertambah.

\section{Kesimpulan}

Dari data yang diperoleh hasil tes dari penggunaan kit IPA saja dan penggunaan kit IPA didahului dengan peragaan PP maupun simulasi dari internet, secara signifikans sangat berbeda. Penggunaan atau kombinasi PP dan internet memberikan hasil yang lebih baik, mempermudah Tutor dan mahasiswa/guru memahami konsep IPA/Fisika, menambah keterampilan, dan kemampuan berinovasi dalam proses pembelajaran IPA/Fisika di SD.

\section{Saran}

Perkembangan IPTEK dewasa ini tidak dapat dipungkiri lagi untuk diterima sebagai bagian dari proses peningkatan sumber daya manusia, dan tidak dapat ditawar lagi untuk diterima sebagai bagian dari proses perkembangan pemdidikan di Indonesia. Melihat kebermanfaatan penggunaan CD PP dan inetrnet pada proses pembelajaran IPA/ Fisika pada mata kuliah berpraktik PDGK 4I07 sangat baik memberikan tambahan kemampuan pemahaman konsep IPA, keterampilan penggunaan alat dan bahan, serta inovatif, maka kelengkapan kit IPA untuk mahasiswa PGSD UT perlu diberikan tambahan perangkat tersebut diatas.

\section{Kepustakaan}

Al-Hakim, Suparlan.(2002). Strategi Pembelajaran Berdasarkan Deep Dialogue/Critical Thinking (DD/CT), P3G, Dirjen Dikdasmen.

Ali, Muhamad. (2003). Teologi Pluralis-Multikultural: Menghargai Kemajemukan Menjalin Kebersamaan. Jakarta. Penerbit Buku Kompas.

Akhmad Sudrajat.(2010).Media Pembelajaran Berbasis Komputer. saddiana73.files.wordpress.com

Banks, J.A. (1993). "Multicultural Educatian: Historical Development, Dimentions and Practrice" In Review of Research in Education, vol. I9, edited by L. DarlingHammond. Washington, D.C.: American Educational Research Association.

Banks, J.A. (I99I). "Multicultural Education: Its Effects on Studies" Racial and Gender Role Attitude" In Handbook of Research on Sociel Teachng and Learning. New York: MacMillan.

Izzatin Kamala. (2008). Makalah Praktikum Pendidikan IPA. Universitas Negeri Yogyakarta

Maman Rumanta.dkk.(2009). Praktikum IPA di SD. Jakarta: Universitas Terbuka

Mujadi.dkk.(20II).Fisika Dasar I. Jakarta:Universitas Terbuka

Izzatin Kamala. (2008). Makalah Praktikum Pendidikan IPA. Universitas Negeri Yogyakarta

Yosapat Sumardi.dkk.(2010).Konsep Dasar IPA di SD.Jakarta: Universitas Terbuka

............pembelajaran-berbasis-multikultural/Dikutip dari http://lubisgrafura.wordpress.com. 2007/09/10/pembelajaran-berbasis-multikultural.

................Interactive Science Simulations: edu.colorado.phet 